\title{
Reseña sobre Guadalupe, C. (ed.) (2021). La educación peruana más allá del Bicentenario: nuevos rumbos. Fondo editorial de la Universidad del Pacífico.
}

\author{
María Amelia Palacios \\ Consejo Nacional de Educación \\ presidencia@cne.gob.pe
}


El propósito del libro según precisa César Guadalupe, editor de la obra, es contribuir a la búsqueda de nuevos rumbos para la educación peruana que partan de una urgente acción de ruptura. Es decir, propone revisar críticamente muchos de los supuestos que han caracterizado y sostenido el "piloto automático" del sector educativo en las últimas décadas.

Los veintidós ensayos y artículos académicos escritos por treinta autores aportan a este propósito tanto con evidencias de investigación como con sugerencias sobre dónde y cómo impulsar rupturas en las prácticas y giros en las prioridades del sistema educativo actual con el fin de garantizar a todas las personas el derecho a una educación de calidad. Desde la investigación académica y el ensayo libre, estos textos contribuyen con conocimiento reciente a la comprensión de algunos de los principales problemas de la educación peruana, y con posibles acciones para avanzar en su solución. Las y los autores problematizan, a lo largo del libro, los sentidos de la educación (qué y para qué educar), los aprendizajes, la formación profesional, la tecnología y la innovación, las desigualdades educativas. Asimismo, discuten elementos que, en la obra, son considerados como impulsores del cambio: la formación y la remuneración docentes, el financiamiento público de la educación, y una nueva organización de los servicios en la educación básica regular.

El libro contiene una serie de preguntas que en sí mismas deberían animar un debate público sobre la educación que el país necesita. Por ejemplo, ¿en qué momento la política educativa perdió - o pareció perder-el rumbo humanista, integrador y complejo que uno lee en los textos clásicos de pedagogía? ¿ $\mathrm{Ha}$ contribuido la escuela peruana a la construcción de ciudadanos libres e independientes? ¿La educación básica y superior logran compensar las desventajas educativas de origen? ¿Qué retos enfrenta la educación para el trabajo? ¿Qué ocurre cuando los estudiantes transitan por toda su experiencia escolar sin conocer a nadie distinto a ellos?

Del conjunto de artículos y ensayos, a continuación, resalto aquellos que problematizan tres políticas públicas que, desde mi perspectiva, requieren de cambios profundos y sostenidos en el tiempo, que exigen las rupturas que anuncia el libro. Se trata de políticas de equidad, de desarrollo docente y de formación ciudadana, las que tienen el potencial de desencadenar otros cambios en el sistema, y que, por consiguiente, deberían ser priorizadas por el Estado y por la sociedad.

Santiago Cueto, Sandra Carrillo y Liliana Miranda se refieren a los altos niveles de inequidad en oportunidades y resultados de aprendizaje que persisten en el país sin que se haya realizado acciones efectivas ni hecho los esfuerzos suficientes para reducirlos. Además de políticas que se centren en elevar las oportunidades para las poblaciones más postergadas, los autores proponen planificar la educación desde una perspectiva de derechos y no solo de eficiencia. Asociadas a la desigualdad de oportunidades educativas, se encuentran la calidad docente - a la que nos referiremos más adelante- y la segregación 164 I escolar. Esta última hace más vulnerables a los pobres y debilita la cohesión 
social. Al no hacer posible el encuentro con otros distintos, no facilita la mezcla con personas con culturas, credos y experiencias diversas, lo cual empobrece la experiencia educativa de las personas y de los pueblos. Incluso en el Perú, la segregación escolar no ha sido reconocida aún como un problema público. Entre las estrategias para reducirla, se propone recuperar el prestigio de la educación estatal, una medida que coincide con uno de los planteamientos del Proyecto Educativo Nacional al 2036 (PEN). Dicho proyecto considera imperativo fortalecer la educación estatal como principal mecanismo para transformar las instituciones educativas en espacios de encuentro entre diferentes. Para lograrlo, se requiere aumentar los recursos destinados a la educación, mejorar las condiciones de trabajo de los docentes, apoyar prácticas innovadoras, e implementar políticas de inclusión de la diversidad en las instituciones educativas.

Otros tres ensayos abordan un impulsor clave del cambio educativo en cualquier sociedad: el desarrollo de los docentes, su formación inicial (Andrea Portugal y Giuliana Espinosa), su autoridad e identidad profesional (Ricardo Cuenca), y sus condiciones sociales y laborales (María Paola Castro y César Guadalupe). Portugal y Espinosa proponen que el conocimiento pedagógico del contenido, el pensamiento complejo y la práctica clínica sean los pilares de un nuevo modelo de formación inicial docente. La evaluación aplicada a egresados de IESP públicos en el 2014 —en la que el 60,5\% y el $86,6 \%$ de los egresados fue calificado en el nivel en inicio en comprensión lectora y alfabetización matemática respectivamente- exige una inversión urgente en el desarrollo personal, ciudadano y profesional de los docentes, dado su rol central en asegurar la calidad de las oportunidades de aprendizaje para los estudiantes.

Cuenca plantea otro problema vinculado con el desarrollo docente: la falta de reconocimiento del saber o conocimiento diferenciado de la profesión. Al no reconocer este conocimiento específico, se le arrebata la autoridad al docente sobre el hecho educativo. El autor resalta que expresiones como las de facilitador y mediador del aprendizaje lo ilustran bien, ya que no se reconoce su rol como productor de conocimiento. Ello pone en cuestión la identidad profesional de los docentes basada fuertemente en la enseñanza.

Una problemática urgente no referida en el libro es la de la formación de los formadores de docentes. Si bien se cuenta con un Perfil Profesional del Formador que describe sus competencias, lo que se plantea en dicho documento es aún una promesa no cumplida, pues el país no cuenta con una política ni un programa de formación de formadores. En la formación docente, la enseñanza en sí misma es motivo de aprendizaje, y la práctica del formador es la que ayuda a los futuros docentes o los docentes en servicio a comprender el proceso de enseñanza de manera cada vez más profunda. Como señala el autor, restituir autoridad pedagógica de los docentes es una vía más segura para fortalecer su responsabilidad profesional con respecto a los aprendizajes.

Un tercer impulsor del cambio tratado transversalmente en varios artículos del libro es la formación ciudadana. La formación para una ciudadanía plena es el principal reto que el Proyecto Educativo Nacional al 2036 plantea 
al país y a quienes lo gobiernen en los próximos quinquenios. El objetivo de la formación ciudadana, según el PEN, es asegurar que cada persona se posicione en su comunidad con un sentido de responsabilidad personal, un ánimo participativo y un sentido de justicia. Los ensayos de Fiorella de Ferrari, Mariana Eguren, Carolina de Beláunde, Liliana Miranda y Sandra Carrillo resaltan la importancia de la educación ciudadana desde distintos ángulos. Reconocen que, si bien enseñar a pensar críticamente no está al servicio exclusivo de la educación ciudadana, es una competencia indispensable para construir ciudadanía. Sin una formación ciudadana que disponga a las personas a participar en los asuntos públicos, a buscar el bien común y a practicar diversas formas de entendimiento social en sus relaciones interpersonales, es inviable construir una sociedad democrática. Sin educación ciudadana, las personas no comprenderán cómo la ley y las normas aportan al bienestar común; no se sentirán comprometidas a participar en la solución de problemas públicos ni controlarán las decisiones de sus representantes elegidos; ni se involucrarán en acciones colectivas para encontrar las soluciones que requiere la comunidad local, regional, nacional o global. Educar en la controversia, enseñar a actuar en la ambigüedad, forma parte de las responsabilidades del sistema educativo. La formación no será integral - como señala Walter Twanama - si reducimos los aprendizajes al saber hacer. Para avanzar en formación ciudadana, los autores mencionan la importancia central de la formación inicial y en servicio de los docentes como vía para asegurar que la escuela sea en sí misma un espacio de convivencia democrática y de formación del pensamiento crítico. Muchas de las dificultades para el diálogo democrático y el debate con posiciones discrepantes que existen en el país se explican por las profundas debilidades institucionales y democráticas que tenemos, entre ellas, las de las instituciones educativas.

En un país en el que el debate argumentado sobre la educación o cualquier otra área de la vida nacional no es una práctica frecuente, en una sociedad en la que solemos confrontar ideas más que debatirlas, un libro como el que reseñamos contribuye a informar y estimular el intercambio de conocimientos y propuestas, tan necesario para la formulación democrática de políticas públicas como para la mejora de la calidad de las prácticas pedagógicas. Recomiendo su lectura a todos los interesados en garantizar el derecho a una educación de calidad a todas y todos los peruanos, no solo porque contiene valiosos análisis e información sobre la educación peruana, sino, principalmente, porque nos invita a pensar cómo responder a problemas y dilemas educativos de larga data que aún continúan irresueltos. 